Шипитько О. Ю.

\title{
Психологические особенности совладающего поведения
} успешно самореализующихся менеджеров по продажам

Статья посвящена психологическому анализу особенностей совладающего поведения успешно самореализующихся менеджеров. Рассматриваются психологические подходы к изучению совладающего поведения с учетом специфики профессиональной деятельности менеджеров по продажам. Анализируются и обобщаются эмпирические показатели совладающего поведения. Предложены результаты эмпирического исследования особенностей совладающего поведения. Приводятся выводы и практические рекомендации на основе проведенного исследования. В статье освещены возможности практического применения полученных результатов.

Ключевые слова: профессиональная деятельность, самореализачия, успешность, совладающее поведение, копинг-стратегии, менеджер, продажи.

В современном обществе выбор профессии определяется не только стремлением к желаемому уровню благосостояния, но и внутренним потенциалом личности, стремящейся к развитию. Менеджеры являются представителями группы профессий «человек-человек», в этой связи они особенно сталкиваются с ситуациями, субъективно воспринимаемыми ими, как трудные, на протяжении всей профессиональной деятельности. В основном, это ситуации стресса, которые по-разному сказываются на личности менеджера, влияя не только на уровень продаж, но и на профессиональное развитие личности. В связи с этим перед психологией встает задача выявления наиболее эффективных стратегий совладающего поведения, учитывая конкретный уровень профессиональной самореализации личности, что в свою очередь способствует эффективности труда и удовлетворенности в целом. Целью нашего исследования является изучение совладающего поведения менеджеров по продажам в профессиональной деятельности в связи с их высоким уровнем самореализации.

В настоящее время под психологическим стрессом понимается несоответствие между профессиональной нагрузкой и имеющимися в наличии ресурсами, сопровождаемое такими эмоциями, как страх, гнев, и т. д. В ходе появления таких эмоций у человека возникает потребность использовать определенную стратегию поведения. В зарубежной психологии этот механизм именуют копинг-стратегией, в отечественной психологии такое поведение принято называть совладающим.

Совладание - это динамический процесс взаимодействия личности и контекстносредовых факторов, который имеет пластичный, гибкий характер, предполагает целенаправленность (в отличие от механизмов защиты) и позволяет преодолевать внутренний диссонанс, обеспечивая выбор адаптивных и адекватных стратегий поведения [4]. Важнейшая функция совладания - это управление внешними и внутренними ресурсами личности. Выбор адаптивной и адекватной стратегии 
позволяет менеджерам по продажам использовать ресурсы таким образом, чтобы максимально реализовать свой внутренний потенциал в этой сложной профессиональной деятельности.

Для того, чтобы понять, какую роль играет совладающее поведение в профессиональной деятельности менеджеров по продажам, рассмотрим несколько наиболее значимых, по нашему мнению, психологических подходов.

Когнитивно-феноменологический подход характеризует стресс как дискомфорт, испытываемый, когда у личности отсутствует равновесие между индивидуальным восприятием запросов среды и ресурсами, доступными для взаимодействия с этими запросами. Однако зачастую именно когнитивная оценка ситуации определяет, является ли она для индивида стрессовой или нет [9]. В этой связи следует отметить, что профессиональная деятельность менеджера по продажам сопряжена со стрессами. Это во многом обусловлено тем, что их деятельность связана с активным общением. Кроме того, менеджерам нередко приходится действовать в условиях недостатка информации, риска и неопределённости. Исследователи копинг-стратегий в попытках систематизировать и создать стройную классификацию выделяют несколько обобщенных уровней того, что предпринимает индивид, чтобы справиться со стрессом: это копинговые действия, копинг-стратегии и копинговые стили. Копинговые действия (то, что индивид чувствует, думает или делает) часто группируются в копинг-стратегии. Стратегии, в свою очередь, группируются в копинговые стили (например, группу стратегий, которая представляет собой концептуально похожие действия). Например, таким стилем может быть «Обращение к другим». Иногда термины «копинговые действия» и «копинг-стратегия» используются как взаимозаменяемые. В то время, как указывают современные исследователи, копинговые стили в целом относятся к действиям или стратегиям, которые последовательно используются индивидом, чтобы справиться со стрессом. Другие похожие термины в этом отношении - это копинговые тактики и копинговые ресурсы [5]. Это во многом обусловлено тем, что в современной психологической литературе можно найти множество классификаций копинг-стратегий.

Эго-ориентированный подход к копинг-поведению, разрабатываемый Н. Хаан, Д. Вейллант и Т. Кроубер, берет свое начало в психоаналитической концепции 3. Фрейда. Суть подхода состоит в дополнительном механизме фрагментации наряду с защитой и совладанием. По их мнению, фрагментация характеризуется терминологией, используемой в случаях дезорганизованного поведения [8]. Следовательно, современные исследования предлагают понимать процесс совладания как специфический эго-механизм, который используется личностью с целью утилизации внутреннего напряжения и дискомфорта.

В основе интегрального подхода к совладающему поведению находятся относительно устойчивые личностные предпосылки, предопределяющие поведение человека на какой-либо стрессовый фактор. Р. Мус выделяет активные и пассивные способы реагирования на стресс, первые считаются проявлением конструктивного поведения, вторые - неконструктивного [10]. Таким образом, в рамках данного 
подхода выбор стилей и стратегий копинг-поведения определяется, как личностными особенностями, так и особенностями эмоционально значимых ситуаций, встречающихся практически ежедневно в трудовой деятельности менеджера.

В отечественной психологии и акмеологии совладающее поведение изучается относительно недавно, с 1990 г. XX столетия, несмотря на это, существует достаточное количество работ на данную тему (Ф. Е. Василюк, 1984; Л. И. Анцыферова, 1994; Л. Г. Дикая., 1996; С. К. Нартова-Бочавер, 1997; А. В. Либина, 1998-2008; И. Г. Малкина-Пых, 2003 и др.). Фундаментальную основу современных работ в этой области составляют труды В. М. Бехтерева, Б. М. Теплова, А. Н. Леонтьева, С. Л. Рубинштейна и др.

Большинство отечественных исследователей (Н. А. Сирота, В. М. Ялтонский, Т. Л. Крюкова, Е. А. Сергиенко и др.) под совладающим поведением понимают особый вид социального поведения личности, обеспечивающего или разрушающего его здоровье и благополучие. По мнению ряда психологов, выбор стратегии совладающего поведения соотносится с образом «Я», а именно: характеристики Я-концепции связаны с выбором основных копинг-стратегий [7]. Таким образом, использование позитивных стратегий совладающего поведения в профессиональной деятельности приводит к формированию положительной Я-концепции, в свою очередь, использование копинг-стратегий со знаком минус ведет к неадекватной самооценке, которая напрямую влияет на уровень профессиональной самореализации менеджера по продажам.

Отечественные специалисты предлагают рассматривать копинг-стратегии как конструктивные и неконструктивные. К первым относят решение задачи, вступление в социальный контакт с коллегами, модернизацию отношения к ситуации, изменения в системе собственных стереотипов и установок. Неконструктивные стратегии способствуют проявлению агрессии, импульсивного поведения, избегания проблем и пассивности в целом [2]. По мнению других специалистов, затрагивающих проблему в этой плоскости, копинг предоставляет возможность осознанно справиться с трудной ситуацией, при этом активно взаимодействуя с окружающей профессиональной средой. Эта идея находит свое отражение в субъектно-деятельностном подходе [1]. Образование эффективного стиля совладающего поведения возникает при наличии активной позиции менеджера, включая активность разного рода (целенаправленную, преобразующую и т.д.) и себя как субъекта этой активности.

С точки зрения сравнительно молодой науки акмеологии, важен аксиологический подход, который раскрывает возможности личностных ценностей как стержня человека [6]. Человек осознает необходимость выбора стратегии поведения на пути к профессиональному росту в профессиональной управленческой деятельности.

В настоящее время общепризнанной классификации типов совладающего поведения не существует, однако практически все они построены вокруг двух глобальных типов совладания со стрессом, выдвинутых Р. Лазарус и С. Фолкман. 
Существуют различные подходы к пониманию совладающего поведения в профессииональной деятельности, рассматривающие копинг-стратегии как специфические процессы, необходимые для осуществления управленческой функции контроля. Спланированные этапы совладающего поведения в трудной ситуации позволяют наиболее грамотно выбрать комплекс стратегий, который будет способствовать развитию профессионального роста с учетом соответствующих возможностей и ресурсов. В свою очередь, ресурсные теории склоняются к определенному комплексу основных возможностей, которые направляют целую базу личностного потенциала в нужное профессиональное русло [3]. Следовательно, ключевые личностные ресурсы являются средством, организующим распределение других ресурсов, непосредственно направленных на повышения уровня продаж и на развитие организационных, а также коммуникативных склонностей.

Итак, эффективность совладающего поведения детерминируется когнитивными ресурсами, которые позволяют понимать личности степень трудности какоголибо события. Однако, как показывают современные исследования, на выбор стратегии копинг-поведения также влияют модальности механизмов совладания со стрессом. Наряду с этим эмоциональные стратегии совладающего поведения проявляются в виде пассивного сотрудничества, приспособления и переживания различных эмоций.

Вместе с тем встречается позиция активного сотрудничества, направленная на решение проблемы и поиск эмоциональной поддержки, характеризующийся поведенческими стратегиями совладания со стрессом в профессиональной деятельности менеджера. В этой связи представляет интерес изучение совладающего поведения успешно самореализующихся менеджеров по продажам.

Гипотеза исследования: мы предполагаем, что одним из условий успешной самореализации в профессиональной деятельности менеджеров по продажам является использование адекватных копинг-стратегий поведения в ситуациях конфликта и стресса.

В эмпирическом исследовании приняли участие 240 респондентов (134 женщины и 106 мужчин) в возрасте от 23 до 50 лет. Выборку составили респонденты, имеющие высшее образование и занимающие должность менеджера по продажам в коммерческих организациях, целью которых является расширение рынка товаров и услуг, а также увеличение прибыли. Поэтому в обязанности таких менеджеров входит не только продажа предполагаемого товара, но и ведение деловых, телефонных переговоров, а также контроль и ведение клиентской базы. Особенности совладающего поведения рассматривались на материале трех групп респондентов, дифференцированных по уровню выраженности профессиональной самореализации в деятельности. Однако в данной статье мы остановимся на рассмотрении совладающего поведения участников исследования с высоким уровнем профессионального саморазвития (44 менеджера, средний возраст которых 36 лет).

Методами исследования выступили: тестирование (Опросник самоактуализирующейся личности Э. Шостром (САМОАЛ), модифицированный А. В. Лазукиным 
и Н. Ф. Калиной, измеряющий общий уровень самоактуализации. Шкала «SACS «Стратегии преодоления стрессовых ситуаций» С. Хобфолла, адаптированная Н. Е. Водопьяновой, Е. С. Старченковой. Методика С. Нормана, Д. Ф. Эндлера, Д. А. Джеймса и М. И. Паркера в адаптации Т. А. Крюковой «Копинг-поведение в стрессовых ситуациях». Опросник К. Томаса «Оценка особенностей реагирования в конфликтных ситуациях», определяющий личностную предрасположенность к конфликтному поведению, выявляющий доминирующие стратегии поведения в трудных ситуациях); методы статистической обработки данных (линейная корреляция по Пирсону, которая применяется для измерения степени линейных связей между переменными).

Результаты, полученные в ходе соответствующих статистических процедур, позволяют утверждать, что у представителей группы с высоким уровнем профессиональной самореализации доминируют определенные стратегии совладающего поведения в трудных профессиональных ситуациях. Согласно результатам исследования, успешность самореализации в профессиональной деятельности менеджеров можно свести к нескольким личностным характеристикам, а именно: «Ориентация во времени», «Потребность в познании», «Креативность» и «Контактность». Перечисленные характеристики взаимосвязаны с определенными копинг-стратегиями поведения и отражаются на успешности и развитии деятельности менеджера.

При анализе корреляционных связей для всей выборки, обнаружена прямо пропорциональная зависимость между условием самореализации «Ориентация во времени» и копинг-стратегией поведения «Осторожные действия» $(r=0,4)$. Выявленная связь демонстрирует ориентацию на решение профессиональных задач. В свою очередь, это дает возможность прогнозировать события и принимать адекватные решения в профессиональной сфере, действуя осторожно, с учетом имеющегося профессионального опыта. Используя данную стратегию поведения в совокупности с другими копинг-стратегиями в нестабильной ситуации, менеджер получает возможность профессионального саморазвития. Это подтверждается в некоторых отечественных исследованиях (Водопьянова, 1998). Далее обнаружена высокозначимая отрицательная связь между условием самореализации «Ориентация во времени» и копинг-стратегией поведения «Эмоции» $(r=-0,4)$. Это свидетельствует об отсутствии ярких эмоциональных реакций в профессиональной деятельности менеджеров по продажам с высоким уровнем самореализации. Личность готова менять эмоциональное отношение к объекту в стрессовой ситуации, что позволяет контролировать рабочий процесс. Затем обнаружена положительная, значимая корреляционная связь между условием самореализации «Ориентация во времени» и копинг-стратегией поведения «Сотрудничество» $(r=0,4)$. Являясь конструктивной стратегий поведения, «Сотрудничество» предполагает наличие активности менеджера, что способствует решению профессиональной задачи только в том случае, если личность ориентируется на настоящие цели организации. Выявлена высокозначимая корреляционная связь, между стратегией поведения 
«Сотрудничество» и личностной характеристикой, способствующей развитию в деятельности «Потребность в познании» $(r=0,5)$. Данная потребность характерна для самоактуализирующейся личности и поэтому подразумевает выбор стратегии, которая обеспечит максимальную эффективность в профессиональной деятельности. В своей деятельности успешный менеджер осознанно стремится к развитию профессиональных знаний и, попадая в ситуации стресса, использует различные манипулятивные приемы для получения нужной информации, что подтверждается наличием корреляционной связи между личностной характеристикой «Потребность в познании» и копинг-стратегией поведения «Непрямые действия» $(r=0,3)$.

Обязательным условием успешно самореализующегося менеджера по продажам является хорошо развитое креативное мышление. Обладая им, менеджер иначе справляется с ситуациями стресса, демонстрируя умение избегать стандартных подходов к решению профессиональной проблемы. В данной плоскости это подтверждается значимой корреляционной связью между условием профессиональной самореализации «Креативность» и копинг-стратегией поведения в стрессовых ситуациях «Избегание» $(r=0,4)$. Нами определена значимая отрицательная связь между условием профессиональной самореализации «Креативность» и копингстратегией поведения в стрессовых ситуациях «Ассертивные действия» $(r=-0,3)$. Учитывая, что деятельность менеджера по продажам требует специфической реакции в конкретных стрессовых ситуациях, для достижения целей организации возникает потребность в манипулятивной модели поведения. Именно поэтому отрицательная связь и говорит об использовании успешным менеджером нескольких путей решения проблемы, в том числе и нестандартных. В свою очередь, условие профессиональной самореализации «Контактность» взаимосвязано с копингстратегией поведения «Решение задачи» $(r=0,3)$. Успех организации зависит от совместной деятельности, как внутри компании, так и с ее внешней средой, поэтому эффективно используя коммуникативные и организаторские склонности, менеджер по продажам решает профессиональные задачи и одновременно развивает профессиональные умения, способствующие его личностному развитию. Затем нами выявлена отрицательная связь между условием профессиональной самореализации «Контактность» и просоциальной стратегией совладающего поведения «Вступление в социальный контакт» $(r=-0,4)$. Это свидетельствует о направленности менеджера по продажам на удовлетворение своих потребностей, а также требований организации, в которой он трудится. Просоциальная стратегия поведения понимается нами как комплекс реакций индивида, характеризующий поступки, совершаемые в пользу своей личности. Полученные нами эмпирические данные являются достоверными ( $p=0,000001)$. По другим показателям значимых взаимосвязей в группе не обнаружено.

Итак, успешно самореализующиеся менеджеры по продажам используют в своей профессиональной деятельности комплекс адекватных стратегий совладающего поведения в стрессовых ситуациях. Профессиональные трудности успешные менеджеры воспринимают как полезный опыт, стремясь к развитию 
собственной карьеры. Предпочтение конструктивных стратегий поведения способствует развитию личности в профессиональной среде и повышает уровень профессиональной самореализации в целом. Рассмотренные нами личностные особенности менеджеров («Ориентация во времени», «Потребность в познании», «Креативность» и «Контактность») во многом определяют выбор стратегий совладающего поведения, способствующих эффективной деятельности организации.

Результаты эмпирического исследования особенностей совладающего поведения успешно самореализующихся менеджеров целесообразно использовать на всех этапах отбора персонала. Полученные данные могут использоваться при обучении, развитии и мотивации менеджеров по продажам.

\section{Литература}

1. Абульханова-Славская К. А. Стратегия жизни. - М., 1991. - С. 270-278.

2. Крюкова Т.Л. Психология совладающего поведения. Монография. - Кострома: КГУ им. Н. А. Некрасова - Студия оперативной полиграфии, Авантитул, 2004.

3. Муздыбаев К. Стратегия совладания с жизненными трудностями // Журнал социологии и социальной антропологии. - 1998. - Т. 1. - Вып. 2.

4. Нартова-Бочавер С. К. «Coping behavior» в системе понятий психологии личности // Психологический журнал. -1997. - Т. 18. - № 5. - С. 20-30.

5. Самыгин С. И. Психология управления. - Ростов-н/Д., 1997.

6. Селезнева Е. В. Общая акмеология / под общ. ред. А. А. Деркача. М.: Изд-во РАГС, 2009. - С. 30

7. Сирота Н. А., Ялтонский В. М., Профилактика наркомании и алкоголизма. М.: Академия, 2003. - С. 24.

8. Haan N. Coping and defending. Process of self - environment organization. - New York Francisco-London: Academic Press, 1977. - P. 3.

9. Lazarus R. S., \& Folkman S. Stress, appraisal and coping. - New York, Springer, 1984.

10. Moos R. H. Coping with life crises: An integrated apporoach. - New York: Plenum Press, 1986. 